\title{
Abductive inference during update: the German preposition mit
}

\author{
Anatoli Strigin \\ Humboldt University, Berlin
}

\section{Introduction.}

Dynamically oriented theories of semantics emphasize the context change potential of sentences. Context change potential depends on the context in which it is computed, since lexical expressions in any natural language tend to display a great number of contextually determined different readings. As context change potential is realized via update operations, updates of discourse record by sentences with such lexical expressions require computing contextual variants. Thus there is a need for a theory (or theories) of how to code the dependency of contextual variants on the context.

In a number of theories dealing with this problem the point of departure is a very general underspecified lexical meaning which is seen as the contextual invariant of the semantics of a lexical expression and is made more specific according to the demands of the communication situation. Attempts to characterize this assumed more general kind of meaning are usually based on deductive mechanisms, using sometimes second-order logic, sometimes more general type systems, and designed so that $T h_{\mathrm{c}} \cup\left\{c_{-}\right.$variant $\left._{\mathrm{LE}}\right\} \mid=\operatorname{sem}_{\mathrm{LE}}$ and $T h_{\mathrm{c}}$ $\cup\left\{\right.$ sem $\left._{\mathrm{LE}}\right\} \quad \mid=\Delta_{1}, \ldots, \Delta_{\mathrm{n}} c_{-}$variant $_{\mathrm{LE}}$ hold, where $\mid=$ is the relation of semantic entailment, $T h_{\mathrm{c}}$ context, sem $\mathrm{LE}_{\mathrm{LE}}$ semantic invariant of lexical expression $\mathrm{LE}$, $c_{\text {_ }}$ variant $_{\mathrm{LE}}$ its variant in context $c$, and $\Delta_{1}, \ldots, \Delta_{\mathrm{n}}$ are the stipulated rules of contextual variation which extend $\mid=$ by allowing the necessary inference. A simple theory of this kind would postulate the invariant to be the disjunction of its contextual variants, and infer the meaning in a context by letting those disjuncts which do not provide a reading in this particular context be false, i.e. let $\operatorname{sem}_{\mathrm{LE}} \leftrightarrow$ $\mathrm{A}_{1} \vee \mathrm{A}_{2} \vee \mathrm{A}_{3}$ and let $T h_{\mathrm{c}}$ entail $\neg \mathrm{A}_{1} \& \neg \mathrm{A}_{2}$. Then $c_{-}$variant $t_{\mathrm{LE}} \leftrightarrow \mathrm{A}_{3}$. Note that $\mathrm{A}_{1}$ and $A_{2}$ are simply false in this context, which is a poor rendering of the unavailability of a reading. More sophisticated theories use more sophisticated rules. The rules and the invariant are sources of difficulties, if contextual variation is strong.

The meaning of the German preposition mit, which roughly corresponds to the English with, in its use as the head of a verbal modifier-PP shows a great contextual variability and depends in its meaning on the meaning of the verb it modifies, i.e. on the thematic structure of the situation. Simple-minded canceling of incompatible disjuncts is insufficient to characterize either its variation or this dependence. Moreover, even more sophisticated theories which use direct deduction seem to be ill equipped to provide such a characterization. Therefore, this paper proposes that update operations wrt. lexical items are based not on merely deductive, but on abductive inferential behavior, subsuming default 
reasoning under the latter. It is assumed that the extreme multiplicity of the contextual variants of mit can be best treated as a case of abductive explanation for a very general invariant relation. The invariant relation is taken to be uninterpreted by itself, except for the type constraints for its two arguments. It therefore becomes plausible to resort to update which is conceived as a kind of explanation for the use of so general a relation; in other words, to explain mit in a context it is necessary to find some element in the situation which entails it. The central problem the paper discusses is how to specify the abducible predicates for mit, i.e. the range of possible choice for its contextual variants. It is suggested that the source of explanatory hypotheses is the semantic structure of the situation typified by the verb, including the world knowledge which stereotypically relates individuals, etc. to a situation. Abductive inference including inference by default implemented in it casts a different light on the structure of lexical knowledge. In particular, since an update is claimed to consist of updating by a general relation and specifying it via abductive rules, there must be a connection between the general and the specific knowledge. The paper expresses this connection, by sentences called Craig interpolants. Using abduction raises objections in general, because it is a complex phenomenon, in particular computationally complex. But abduction in the lexicon is claimed here to be restricted by a situation parameter which narrows down the choice of hypotheses, and makes it tractable, presumably. Though the paper uses only mit to argue the case, it seems that the overall picture of the lexicon in which abductive inference is used might give a new impetus to describing the meaning of other prepositions with the meaning dependent on other meanings, and, perhaps, such phenomena as argument selection.

\section{The data on mit, simple update and the problem of contextual variation.}

The main character of this paper is the German preposition mit which generally corresponds to the English with. The case under investigation is the verbal (sentential) modifier mit which is taken to be a two-place relation, the modified argument being of the type of situations, $\mathrm{D}_{s}$, the complement is of the type of entities in general, $\mathrm{D}_{\mathrm{e}}$, i.e. $\|m i t\| \in 2^{\mathrm{D}_{\mathrm{e}} \mathrm{X}_{\mathrm{s}}}$. Modifiers like ein Buch mit Bildern ( $a$ book with pictures) will not be considered. The edge between modifiers and arguments is very narrow, and, if there is no need to draw the distinction, I will not, which does not mean that the distinction is unimportant, only that I will try to ignore it whenever possible, and try to stay clear of arguments. Observations about mit show an extreme variability of its meaning; starting from something like ' $x$ is instrumental in s' in (1) we end with some poetical licenses which nevertheless are interpretable without a dictionary ( $h-j$ are due to Eroms, 1981).

(1)a. Karl schneidet den Fisch mit dem Messer

Karl cuts the fish with the knife

'Karl cuts/is cutting the fish with the knife' 
b. er blamiert sich mit seiner Rede

he makes-a-fool-of himself with his speech

'he made a fool of himself with his speech'

c. er machte mit einer Zitronenplantage Pleite

he made with a lemon-plantation bankruptcy

'he went broke with a lemon plantation'

d. er riß die Pflanze mit der Wurzel heraus

he tore the plant with the root out

'he tore the plant out by the root'

e. er fiel mit dem Gesicht zur Erde

he fell with the face to-the ground

'he fell with his face to the ground'

f. er starte sie mit offenem Munde an

he stared her with open mouth at

'he was staring at her with (his) mouth open'

g. Peter wäscht das Auto mit Sorgfalt

Peter washes the car with care

'Peter is washing/washes his car with care'

h. Übrigens, mit dem roten Beutelchen wurde ich von ihr sehr ausgelacht by-the-way, with the red bag-little was I by her very laughedout

'by the way, I was very much laughed at by her on account of the little red bag' (Hesse, Steppenwolf)

i. 'Die Augen fließen mit Tränen the eyes are streaming with tears

j. ?? ...Dörfer, deren Wege alle mit fröhlichen Kirchgängern zurückkamen

... villages, which roads all with joyful churchgoers back-came

'... villages, the roads of which returned full of joyful churchgoers'

(Jean Paul)

The number of separate meaning classes was sometimes claimed to be as many as thirty, e.g. Mandel (1957). Ten seem to be usual (Schröter, 1990). Constraints on the variability of mit stem mainly from the character of the situation described by the verb and from the semantics of the complement DP of mit. The fact that verbs can be useful in classifying the uses of mit seems not to have been considered important. This reluctance to pay attention to the verb is puzzling. Consider (2).

(2)a. John zerbrach den Spiegel mit einem Hammer/mit Maria

John broke the mirror with a hammer/with Maria

b. *der Spiegel zerbrach mit einem Hammer/mit Maria

* the mirror broke with a hammer/with Maria

c. der Spiegel zerbrach

the mirror broke

Although both (2)a. and c. can be used to describe the same situation, b. seems to be impossible, and not simply true or false. If the meaning of mit were a 
disjunction of its contextual meanings, we would expect this particular instrumental/agentive meaning be still present in (2)b. It seems there is a dependence of the meaning of mit on the meaning of the verb it modifies.

I will propose that mit picks out some role for its complement determiner phrase (or noun phrase; the distinction is unimportant in this context) in this situation, the role which can be filled by an object in the described situation, but which need not be explicitly stated or required by the verb as its argument in the context; the type of situation in (2)b. can then be taken not to contain the instrumental role, which is therefore unavailable for mit. I will define what might be called the structure or the type of the situation to make this idea more precise in section 3. The dependence on the properties of the complement noun phrase of mit is somewhat more complex. Consider (3).

(3)a. sie segelten mit dem Wind they sailed with the wind

b. * sie fuhren mit der Strasse *they drove with the street

c. *sie standen mit dem Wind *they stood with the wind

Wind being a kind of movement, it has an inherent directional component; this component is lacking in case of the street. Stative verbs do not allow this meaning of mit either.

The roles do not cover all possible relations in German; locative relations like 'over', 'in', or 'beside' are no interpretations of mit, hence I will assume that they seem to be, in general, excluded from defining the type of situation, though not from characterizing it.

Examples (1)e.-g. and (3)a. suggest that either the notion of the structure of situation should be made very broad, or there is some other source of the interpretation of mit-PPs. I will assume that it is stereotypical knowledge relating objects of particular kinds to the situation of a particular type which provides additional variation space for $m i t$, cf. (4).

sie schwimmt immer mit der Badekappe she swims always with the bathing-cap 'she always swims with a bathing cap'

There is a weak (perhaps default) inference that the bathing cap is on her head. Given that the information in the sentence is used to update any conversational record, it is difficult to maintain that a specific variant of mit is used at once. It is more plausible that we update by an underspecified relation, $\operatorname{cmt}(\mathrm{a}, \mathrm{e})$, and use the context to specify it further. I will use discourse representation theory (Kamp \& Reyle, 1993) to exemplify the ideas of this paper. A simplified DRS for John schneidet Fisch mit einem Messer (John cuts fish with a knife) is given in Fig.1. 
The relation $c m t(e, v)$, read ' $v$ is concomitant with $\mathrm{e}^{\prime}$ represents the underspecified/general/context-invariant meaning of $\mathrm{mit}$.

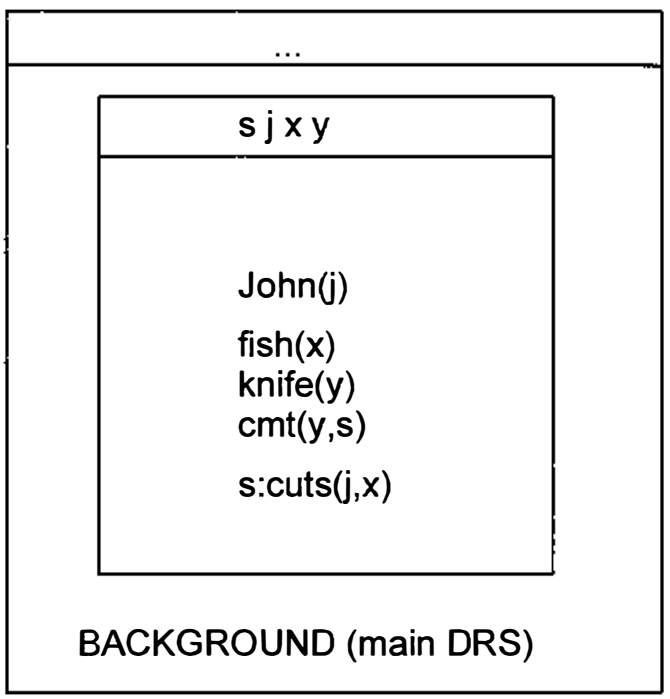

Fig 1.

Though the structure of the situation must be specified in more detail, this format will do to consider the problem of the mechanism generating the contextual meanings of mit, its contextual variants, as well as the restrictions on the variation domain. Theories using deductive reasoning are explanatory too weak for this.

Thus, e.g. the theory of conceptual shift found in a number of variations in the work of Bierwisch and others, e.g. (Bierwisch, 1989), (Bierwisch, 1983), (Dölling, 1994) assumes that a lexical entry contains the conceptually invariant part of a family of context meanings, its Semantic Form, SF; the lexical knowledge derives the contextual variants of this SF, and the conceptual system of the brain derives the specific instances of these contextual variants. The SF-tocontextual-variant derivation is effected by a system of shifting functions. An example based on Bierwisch (1983), but changed slightly for the purposes of this paper, is the shift from some processes to organizations where these processes occur, and to buildings where they are located effected by (ii) and (iii) in (6).

(6) the opera lasted three hours vs. is in debt $v s$. is at the comer

(i) $\mathrm{SF}$ (opera) $=$ sem, some set of operatic processes

(ii) $\lambda \mathrm{P} \lambda$ (y:abstract) $\exists(\mathrm{x}$ :abstract_process) $[\mathrm{P}(\mathrm{x}) \&$ organization_for $(\mathrm{y}, \mathrm{x})]$

(shift to organizations)

$\lambda(y: a b s t r a c t) \exists\left(x: a b s t r a c t \_p r o c e s s\right)[\operatorname{sem}(x) \&$ organization_for $(y, x)]$ 
(iii) $\lambda \mathrm{P} \lambda$ (y:artefact) $\exists(\mathrm{x}:$ abstract_process) $[\mathrm{P}(\mathrm{x}) \&$ building_used_for $(\mathrm{y}, \mathrm{x})]$ (shift to buildings)

$\lambda$ (y:artefact) $\exists\left(\mathrm{x}: a b s t r a c t \_p r o c e s s\right)[\operatorname{sem}(\mathrm{x}) \&$ building_used_for(y,x)]

In case of mit some problems would be difficult to solve. There are too many shifters, they are not generalizable to other words, ad-hoc, and there seems to be no reason for the domain restriction. Lexical coercion in the sense of Pustejovsky (Pustejovsky \& Boguraev, 1993) is not directly applicable, because there is no need to coerce types.

I suggest that the computation of contextual variants makes use of procedures best described as hypothetical reasoning.

\section{Specification by abduction, explanations and contextual variants of mit}

Suppose somebody hears a sentence $\varphi$ with mit. Simple update implies she updates her knowledge with the result of the semantic processing of $\varphi$, in particular with some proposition informally renderable as $\operatorname{cmt}(\mathrm{a}, \mathrm{s})$ for some discourse referents a, s; but if $\operatorname{cmt}(\mathrm{a}, \mathrm{s})$ is a very general relation, it does not contribute to the contextual information of the hearer. A more informative update would add not merely $c m t(a, s)$, but either use contextual information to deduce its more specific instance, or provide an explanation of its use. The basic idea here is to assume that any contextual variant of $c m t(\mathrm{a}, \mathrm{s})$ implies $c m t(\mathrm{a}, \mathrm{s})$, so that it can be considered an explanatory hypothesis of $\operatorname{cmt}(\mathrm{a}, \mathrm{s})$ in the context, and this relevant hypothesis is the contextual meaning of $\operatorname{cmt}(\mathrm{a}, \mathrm{s})$. This is abductive reasoning, the term due to Peirce (1955). It can be illustrated using implication to contrast it with deduction by the rule of modus ponens. The deduction goes like if $p$ implies $q$, and you observe $p$, then deduce $q$ ', whereas abduction goes like (7), i.e.

$$
p \rightarrow q q
$$

'if $\mathrm{p}$ implies $\mathrm{q}$, and you observe $\mathrm{q}$, then it may be the case that $\mathrm{p}$ obtains'. A typical example of this kind of reasoning is (8) (Pearl, 1987).

$$
\begin{aligned}
& \text { rained-last-night } \rightarrow \text { grass-is-wet } \\
& \text { sprinkler-was-on } \rightarrow \text { grass-is-wet } \\
& \text { grass-is-wet } \rightarrow \text { shoes-are-wet } \\
& \text { observe shoes-are-wet } \\
& \text { explain shoes-are-wet by rained-last-night }
\end{aligned}
$$

The explanation grass-is-wet is not basic, one is usually interested in hypotheses which are not further explainable. The hypothesis sprinkler-was-on is an alternative hypothesis, so the space of abducibles must be restricted, or some choice criteria should be given to choose one explanation. This is a general problem. It is often assumed that the hypotheses are given by the proof procedure, but this could be too liberal a characterization of the use of abduction in meaning specification. Formally, however, the explanation space can be thought of as fixed beforehand. Suppose this is done. Then a new relation can be defined (Poole 
1987,1988 ) and used in inferring the contextual variants of underspecified meanings. This relation will be defined in two steps, $(A)$ and $(A D)$ in the language of first order logic.

Let $\Gamma$ be a set of facts; they cannot be contradicted or ignored. Let $\Pi$ a set of possible hypotheses, formulae without quantifiers, but possibly with open variables, and $P$ a subset of the ground instances of $\Pi$. Ground instances are instantiations of open variables by constants which can be supplied in the form of discourse referents during processing.

(A) $\Gamma \cup \mathrm{P}$ explains $\varphi, \Gamma \cup \mathrm{P}>>\varphi$, iff

(i) $\Gamma \cup P \mid=\varphi$

(ii) $\Gamma \cup \mathrm{P}$ is consistent

Since the notions used are first order, derivability, - , can be used instead of semantic notion of entailment $\mid=$. Consider an example of such hypothetical reasoning: suppose it is known that instruments play some role in situations. Let $\forall \mathrm{y} \forall \mathrm{e}(\operatorname{instrument}(\mathrm{y}, \mathrm{s}) \rightarrow \operatorname{role}(\mathrm{y}, \mathrm{s})) \in \Gamma$ be this knowledge. We know that instrument $(\mathrm{y}, \mathrm{s}) \in \Pi$, and observe $\operatorname{role}(\mathrm{a}, \mathrm{s})$, then $\mathrm{P}=\{\operatorname{instrument}(\mathrm{a}, \mathrm{s})\}$ is the hypothesis which explains the observation $\operatorname{role}(\mathrm{a}, \mathrm{s})$ together with $\Gamma$, i.e. $a$ plays a role in $s$ because it is instrumental in $s$. This framework allows to also use open formulae of the form $\psi \rightarrow \varphi$ as hypotheses, formalizing default reasoning. Let $\Gamma$, $\Pi, P$ be as above, $\Delta$ a set of defaults. Let $D$ a set of ground instances of defaults in $\Delta$. Call $\mathrm{D} \cup \mathrm{P}$ a scenario. Then ' $\varphi$ is explainable' is defined by $(\mathrm{AD})$.
(AD) $\Gamma \cup \mathrm{D} \cup \mathrm{P}>>>$ iff
(i) $\Gamma \cup \mathrm{D} \cup \mathrm{P} \vDash \varphi$
(ii) $\Gamma \cup \mathrm{D} \cup \mathrm{P}$ is consistent

i.e. there is a scenario $\mathrm{D} \cup \mathrm{P}$ explaining $\varphi$. Suppose $\Gamma$ is empty, $\operatorname{instrument}(\mathrm{y}, \mathrm{s})$ $\in \Pi$, and it is known that instruments play a role in situations as a rule, but not always, i.e. $\Delta=\{$ instrument $(\mathrm{y}, \mathrm{e}) \rightarrow \operatorname{role}(\mathrm{y}, \mathrm{e})\}$ now. Then, if $\operatorname{role}(\mathrm{a}, \mathrm{s})$ is observed, it is explained by $\{$ instrument $(\mathrm{a}, \mathrm{s})$, instrument $(\mathrm{a}, \mathrm{s}) \rightarrow \operatorname{role}(\mathrm{a}, \mathrm{s})\}$ using the default.

In case of specifying the contextual meaning of mit, $\Pi$ is the set of its contextual variants when instantiated with discourse referents, call it $\Pi_{\text {mit }}$. So the meaning of mit in the context c, $c m t_{c} \in \Pi_{\text {mit }}$, explains $c m t$, i.e. $c m t_{c} \gg>c m t$ for some contextually relevant $\Pi_{\text {mit }}$. The application of defaults will be taken up in the following section.

\section{Situation schemata as $\Pi_{\text {mit }}$ thematic structure, and local abduction}

$\Pi_{\text {mit }}$ is given by the situation type defined by the verb. The word 'situation' is used here in two ways. In the first sense, situations are in the world 'out there', in the second situations are a cognitive indexing device ${ }^{1}$. A situation scheme is then a 
set of rules which representationally interpret a verb. Warrington (1978) showed that there are two subsystems of the processing of the information about objects, the perceptual and the conceptual ones. The first identifies, e.g., whether two presented objects are simply two views of one and the same object, the second is a mapping of the schemes in the perceptual identification system to the more conceptual schemata, and allows to draw inferences about objects. Patients with one kind of brain damage were unable to identify an oboe when simply presented in an untypical perspective, but 'recognized it' when it was named; others, with a different damage, were sure that it was the same object under both perspectives, but were unable to explain its properties, its use, or to relate it to other objects in general. Extrapolating these findings to the case of situations, it seems reasonable to assume that there are two systems involved in building situations, too. One of them takes care of perceptually defined aspects of identifying whether the world at some particular time is in some situation, the other constructs a mapping of such perceptual subsystems to general conceptual systems. Hence there must be an interface between the two systems. Searle (1980) argued that there are aspects of knowledge which provide some general conceptual background for the meaning ${ }^{2}$. Take the verb cut. Cutting grass, paper or a cake are activities, differing, in particular, in the instruments that are used, and in the overall results. This background is the required interface. In other words, we have sometimes perceptually and always contextually grounded categorization patterns which I will call here situation schemata. They will be assumed to contain $\Pi_{\text {mit }}$. Situation schemata are therefore sets of first order formulae with open variables, and have three structuring factors: event structure, relational structure, and thematic structure. Event structure specifies such properties as whether the situation involves one or two events, is a process, etc. Relational structure specifies the relations which hold between the entities of the event structure, like causality, contingency, temporal structure. Semantically the most important part of a situation schema is its thematic structure. The cutting situation described by schneiden could look like (9) in case of cutting with scissors. Note that this theory is a set of hypotheses, except for the name of the situation, which is treated as a fact during update. It provides the connections among different subsystems relating to the same phonological form cut, etc..

$$
\begin{aligned}
& \text { Situation-name: cut( }(\mathrm{s}) \\
& \text { in }(\mathrm{s}, \mathrm{e}), \text { in }\left(\mathrm{s}, \mathrm{e}^{\mathrm{e}}\right), \\
& \text { e causes } \mathrm{e}^{\prime} \\
& \text { terminates }\left(\mathrm{e}^{\prime},\right. \text { prestate) } \\
& \text { initiates }\left(\mathrm{e}^{\prime}, \text { poststate }\right) \\
& \text { whole-at }(\mathrm{y}, \text { prestate) } \\
& \text { cut-at }(\mathrm{y}, \text { poststate }) \\
& \chi \text {-time }(\mathrm{e}, \mathrm{t})
\end{aligned}
$$




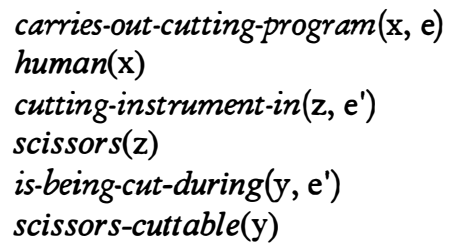

The name cut(s) gives access to the four eventualities of the event structure: the agentive event, the cutting event itself, the state of the theme (or patient) before the cutting event, and its state after the cutting event. The two temporal predicates terminates and initiates are described in Kovalsky and Sergot (1986), $\chi$-time(e,t) specifies which time serves as a natural unit for the agentive event ${ }^{3}$. Other aspects of the formal relationship between events, states and times are specified in some conceptual theory of these factors, e.g. that any change of state is a result of some event, by default, etc.. Relational structure encodes that it is a causative situation, and characterizes the relations between states and/or events, e.g. it characterizes the state of the theme before and after the cutting event. Words like 'theme' characterize properly the third aspect of the situation scheme, its thematic or $\theta$ structure. It relates objects which help to anchor the situation itself in the world to the events and states in the situation. These characteristics should be sufficiently detailed to take care of very specific inferences which allow us, e.g., to have expectations: if I ask somebody to cut the cake, I expect that she would use a knife rather than a scimitar or a lawn mower. But such detailed situation schemata are better not be taken as verb meanings. Verb meanings are constructed by another generalization, as Dowty (1991) suggested ${ }^{4}$. They are stated in terms of $\theta$-roles, which are defaults classifying the contextually explicit relations of a situation scheme, e.g. if the relation carries-out-cutting-program $(\mathrm{x}, \mathrm{e})$ is interpreted in the situation of cutting paper, then it is classified as an agentive relation at the next level of semantic abstraction by a prototype of causal situations, i.e. by a situation type.

$$
\begin{aligned}
& \text { cut }(\mathrm{s}), \operatorname{in}(\mathrm{s}, \mathrm{e}), \operatorname{in}\left(\mathrm{s}, \mathrm{e}^{\prime}\right), \\
& \text { carries-out-cutting-program }(\mathrm{x}, \mathrm{e}) \& \text { e causes } \mathrm{e}^{\prime} \rightarrow \operatorname{agent}(\mathrm{x}, \mathrm{s}) \\
& \text { cutting-instrument }\left(\mathrm{z}, \mathrm{e}^{\prime}\right) \& \text { e causes } \mathrm{e}^{\prime} \rightarrow \operatorname{instrument}(\mathrm{z}, \mathrm{s}) \\
& \text { is-being-cut-during }\left(\mathrm{y}, \mathrm{e}^{\prime}\right) \& \text { e causes } \mathrm{e}^{\prime} \rightarrow \operatorname{theme}(\mathrm{y}, \mathrm{s})
\end{aligned}
$$

Given this formalization of situation and situation types, to get the interpretation of mit we connect it to thematic structure. One part of the interpretation of mit would explain $\operatorname{cmt}(\mathrm{a}, \mathrm{s})$ by looking for a hypothesis in the situation $\mathrm{s}$ which is instantiated by $a$ using $\theta$-roles as defaults. If such a hypothesis is consistent with the facts, it is the contextual meaning of mit. Presumably, $\theta$-roles are a special kind of relation. If we collect all $\theta$-roles relevant in the situation under the predicate role $(\mathrm{x}, \mathrm{s})$ by the defaults like the ones in (11) 
(11) $\operatorname{agent}(\mathrm{x}, \mathrm{s}) \rightarrow \operatorname{role}(\mathrm{x}, \mathrm{s})$ instrument $(z, s) \rightarrow \operatorname{role}(z, s)$

theme $(y, s) \rightarrow \operatorname{role}(y, s)$

then $\operatorname{cmt}(\mathrm{a}, \mathrm{s})$ will be connected by the default to $\theta$-roles via the default (12)

(12) $\quad \operatorname{role}(\mathrm{a}, \mathrm{s}) \rightarrow \operatorname{cmt}(\mathrm{a}, \mathrm{s})$

The default (12) is the inference rule used to specify contextual variants of mit, and motivates the term thematic preposition wrt. mit.

\section{Abducing to thematic structure}

The update stopped as shown in Fig. 1. Now it may be continued to yield Fig. 2, by substituting ground instances of the situation type for cut; the discourse referents of Fig. 1 are modified accordingly.

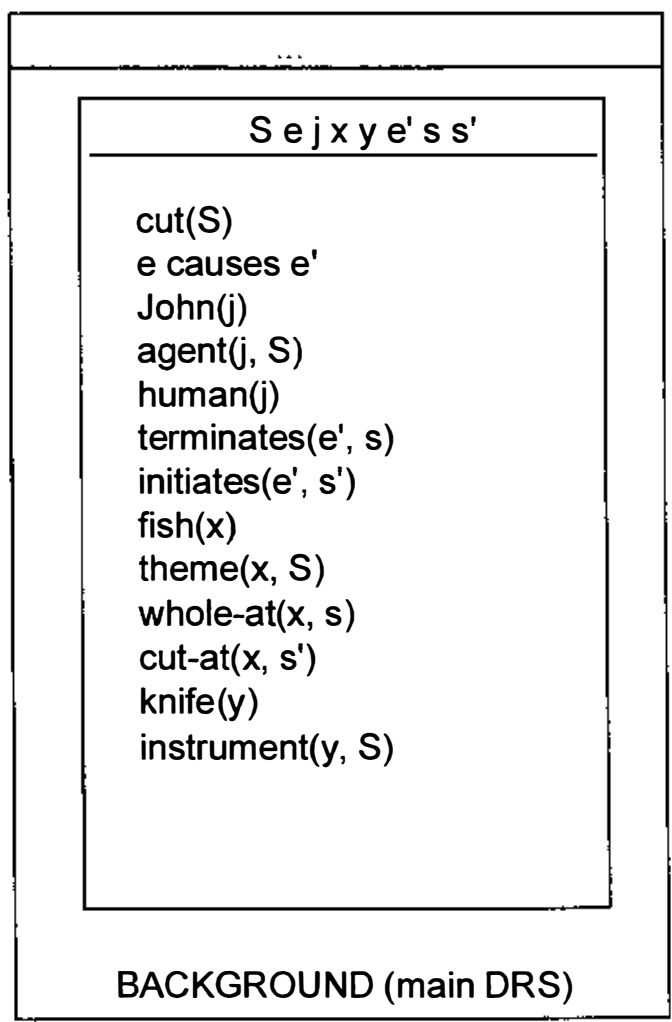

Fig 2. 
The predicate $\operatorname{cmt}(\mathrm{y}, \mathrm{S})$ is explainable e.g. by the hypothesis instrument $(\mathrm{y}, \mathrm{S})$, the latter is explained as shown in the scenario (13),

(13) $\left\{\operatorname{cut}(\mathrm{S})\right.$, e causes $\mathrm{e}^{\prime}$ cutting-instrument $\left(y, e^{\prime}\right) \&$ e causes $\mathrm{e}^{\prime} \rightarrow$ instrument $(\mathrm{y}, \mathrm{S})$, instrument $(\mathrm{y}, \mathrm{S}) \rightarrow \operatorname{role}(\mathrm{y}, \mathrm{S}), \operatorname{role}(\mathrm{y}, \mathrm{S}) \rightarrow \operatorname{cmt}(\mathrm{y}, \mathrm{S})\}$

therefore cutting-instrument $\left(\mathrm{y}, \mathrm{e}^{\prime}\right) \gg>\operatorname{cmt}(\mathrm{y}, \mathrm{S})$, i.e. it is a basic explanation. Since the knife is inanimate, $\operatorname{cmt}(\mathrm{y}, \mathrm{S})$ is not explainable via agent, it is not knifecuttable, as a rule, so not a theme. Once the relation $\operatorname{cmt}(\mathrm{y}, \mathrm{S})$ has been explained, it can be dropped from the DRS, and the update is finished. The hypothesis e causes $\mathrm{e}^{\prime}$ is needed, since instruments occur only in causative situations.

The preposition mit has also what is termed comitative use, e.g. (14).

(14) John schneidet Fisch mit Marcia

John cuts fish with Marcia

One explanation is provided by the scenario in (15)

$\left\{\operatorname{cut}(\mathrm{S}), \mathrm{e}\right.$ causes $\mathrm{e}^{\prime}$

carries-out-cutting-program $(\mathrm{m}, \mathrm{e})$ \& e causes $\mathrm{e}^{\prime} \rightarrow \operatorname{agent}(\mathrm{m}, \mathrm{S})$,

$\operatorname{agent}(\mathrm{m}, \mathrm{S}) \rightarrow \operatorname{role}(\mathrm{m}, \mathrm{S}), \operatorname{role}(\mathrm{m}, \mathrm{S}) \rightarrow \operatorname{cmt}(\mathrm{m}, \mathrm{S})\}$

hence carries-out-cutting-program $(\mathrm{m}, \mathrm{S}) \gg>c m t(\mathrm{~m}, \mathrm{~S})$. Another explanation of the relation $\operatorname{cmt}(\mathrm{m}, \mathrm{S})$, the one via the instrumental role for Marcia is only implausible due to defaults for instruments/people; the way Marcia carries out the cutting program in this co-agentive use is a matter of world knowledge entirely, hence it cannot be deduced or abduced in this context, and we cannot say whether she is just being cheerful, or is holding a second knife. At this point we are in the position to explain the facts in (2)b. If the thematic structure of the situation type of cut in (2)c. contains no agentive event $e$, but only the thematic event $e^{\prime}$, neither agent(Marcia,e), nor instrument (Hammer,e) are abducibles.

It seems to be clear how mit can be considered a very general thematic preposition. But its use is broader than that, and includes also abduction to the stereotypical knowledge about participants in the situation.

\section{Abducing to stereotypical knowledge \& semantic descent}

To account for sentences like (16), $\Pi_{\text {mit }}$ must be extended. Assume that $\Pi_{\text {mit }}$ is a set of hypotheses about a situation. They arguably include relevant knowledge which does not structure the situation, but nevertheless is important in forming expectations in situations of the same type, so it can be characterized as stereotypical wrt. the situation. Any situation-indexed subset of $\Pi_{\text {mit }}$ is then within a situation scheme by virtue of being either the thematic knowledge, or the 
stereotypical knowledge. So the explanation of the use of mit in (4), repeated here as (16),

Sie schwimmt mit der Badekappe

she swims with the bathing-cap

would go like this: bathing caps are stereotypically put on during swimming, so she must have a cap on. However, there are two problems here. First, since situations do not put bathing caps on, but their agents sometime do, we need a kind of semantic descent from situations to their agents. Second, we have to specify the form stereotypical knowledge is put into. I will introduce the descent first, and then motivate the particular form it is cast into.

To characterize relations in a situation as stereotypical in it a new default theory is needed. It should be marked by a predicate different from role. The latter should involve at least two individual discourse referents for the stereotypical relation, and one for the situation. Let (17)a. be the way stereotypical relations are marked in the situation $S$ of type $\tau,(17 \mathrm{~b})$ be the default which permits the use of this information for $c m t$ similarly to role, and $R\left(\mathrm{x}, \mathrm{y}, \mathrm{S}_{\tau}\right)$ be some stereotypical relation accessible in $S$.

(17)a. $R\left(\mathrm{x}, \mathrm{y}, \mathrm{S}_{\tau}\right) \rightarrow$ stereotype $\left(\mathrm{x}, \mathrm{y}, \mathrm{S}_{\tau}\right)$

b. stereotype $\left(\mathrm{x}, \mathrm{y}, \mathrm{S}_{\tau}\right) \rightarrow \operatorname{cmt}\left(\mathrm{y}, \mathrm{S}_{\tau}\right)$

This piece of knowledge provides us with the explanation for $\mathrm{cmt}$, provided we know that $\mathrm{y}$ is involved in $\mathrm{S}_{\tau}$. Consider (16) again. Let (18) be some default knowledge about bathing caps.

(18) bath-cap $(\mathrm{y}) \rightarrow(\operatorname{agent}(\mathrm{x}, \mathrm{S}) \& \operatorname{swim}(\mathrm{S}) \rightarrow($ is_on $(\mathrm{y}, \mathrm{x}, \mathrm{S}))$

This stereotypical knowledge involves both bathing caps and swimming situations. It connects the two. So we may conclude that it is marked as a stereotype for situations of the type $\operatorname{swim}(\mathrm{S})$.

(19) $($ bath-cap $(\mathrm{y}) \rightarrow(\operatorname{agent}(\mathrm{x}, \mathrm{S}) \& \operatorname{swim}(\mathrm{S}) \rightarrow($ is_on $(\mathrm{y}, \mathrm{x}, \mathrm{S}))) \rightarrow \operatorname{stereotype}(\mathrm{x}, \mathrm{y}, \mathrm{S})$

The scenario in (20) explains $\operatorname{cmt}(\mathrm{y}, \mathrm{S})$, provided we have a swimming situation $S$, and an agent $x$ in it on the one hand, and a bathing cap $y$ on the other as facts. Again, $\operatorname{cmt}(\mathrm{y}, \mathrm{S})$ is the first step in the update which is discarded the moment it is explained.

(20) \{ $\operatorname{swim}(\mathrm{S})$, bath-cap $(\mathrm{y}), \operatorname{agent}(\mathrm{x}, \mathrm{S})$,

$($ bath-cap $(\mathrm{y}) \rightarrow(\operatorname{agent}(\mathrm{x}, \mathrm{S}) \& \operatorname{swim}(\mathrm{S}) \rightarrow($ is_on $(\mathrm{y}, \mathrm{x}, \mathrm{S}))) \rightarrow \operatorname{stereotype}(\mathrm{x}, \mathrm{y}, \mathrm{S})$, stereotype $(\mathrm{x}, \mathrm{y}, \mathrm{S}) \rightarrow \operatorname{cmt}(\mathrm{y}, \mathrm{S})\}$ 
Whether or not some relation is thought of as stereotypical depends on a lot of factors like how useful it is to assume it as a part of the stereotype of a situation. This is different from the QUALIA structure. Consider (20) again. A possible way of looking for a suitable relation might be to assume that the telic role wit. the QUALIA structure of bathing caps is to be put on during swimming. But this does not seem to be sufficient. In (21) we still have the idea that an umbrella is involved in the situation, so abduction would be more appropriate, since umbrellas cannot involve bathing in their telic roles.

\section{(21) She bathes with an umbrella}

So stereotypical knowledge about situations is really required, i.e. to know that bathing usually happens on a beach, the sun shines there, umbrellas protect from the sun, so she might have an umbrella with her, probably even while bathing, but this is implausible.

The idea of how to construct the predicate stereotype $(\mathrm{x}, \mathrm{y}, \mathrm{S})$ is based on a result about first order languages known as the Craig lemma. The underlying reasoning assumes that any contextual variant of $\mathrm{cmt}$ implies it. The problem in the particular case of (16) is how to turn a statement is_on $(\mathrm{y}, \mathrm{x}, \mathrm{S})$ about object $x$ which is related to the situation $S$ into a statement $c m t(\mathrm{y}, \mathrm{S})$ about situation $S$. There must be a predicate which connects the two. There is one sort of connecting predicates which is guaranteed by the Craig lemma. So such predicates were used to define stereotypical knowledge. The predicate stereotype $(\mathrm{x}, \mathrm{y}, \mathrm{S})$ is a Craig interpolant ${ }^{6}$.

The use of Craig interpolants in stereotypical knowledge is not an ad hoc solution. There are other cases which are amenable to a similar treatment. Note that the descent from situations to their agents is not a distinct operation. Perhaps some additional principles of inferencing are needed, too, which may, quite in the spirit of the conceptual shift theory, be termed conceptual descent from situations to their participants, or like QUALIA structure and type coercion, allowing to substitute related predicates for the original ones by enlarging their extensions in constrained and systematic ways. The descent from situations to their participants should allow to speak about loud events by implicitly defining a loudness measure on events in terms of loudness measure of some sounds which are involved in the events, for instance. This device is involved, e.g. in German verbs like überschreien (overshout) which are constructed around two events measured in terms of the shouting done in them. Another case of this sort seems to be (22), which raises the problem of localizing restrictions for the semantic descent.

(22) John schneidet Fisch mit Vergnügen

John cuts fish with delight

Mental attitudes are attributed to living beings, not to situations. Human agents in causative situations are bearers of mental attitudes, perhaps stereotypically so, but note that fish is inaccessible as the bearer of the attitude not because it is nonhuman, but because it is a theme. The descent from situations to participants in them is a default operation, too, so there is no default to the effect that themes 
have attitudes, which is somehow connected to the volitional component of agentivity, presumably.

\section{Interpolants as means of extending predicates}

Example (23) seems to present a problem to the approach so far. It also seems to be unclear, why $b$. and c. are unacceptable.

(23)a. sie segelten mit dem Wind they sailed with the wind

b. ?? sie fuhren mit der Straße they drove with the street

c. ?? sie standen mit dem Wind they stood with the wind

But it can be argued that the interpretation of the sentence is 'they sailed in the direction of the wind', and this interpretation is restricted to predicates denoting intrinsic motion, like wind, on the one side, and to motion predicates like sail on the other. Consider cases like mit dem Fluß schwimmen (to swim with the river/with the flow), mit der Luftströmung schweben (to float/glide/soar with the air current), mit dem Verkehr fahren (to drive with the traffic). They seem to justify such an interpretation. Prerequisite to an implementation along these lines is something like a conceptual shift from the motion itself to its direction, e.g. wind is extended to cover the direction of the wind. The extension is unwarranted for street, hence the unacceptability of (23)b. Craig interpolants can be put to use here, too. Since the wind has an inherent direction, let it be represented in (24)by a Skolem function $\operatorname{dirwind}(\mathrm{y})$.

(24) $\operatorname{wind}(\mathrm{y}) \rightarrow \operatorname{is}-\operatorname{direction}(\mathrm{y}, \operatorname{dirwind}(\mathrm{y}))$

Assume that in some situations we can shortcut, and use the word wind to refer to its direction. Let such a shift be coded by the scheme (25) in general.

(25) $P(\mathrm{x}, \mathrm{S}) \rightarrow($ use-for $(\mathrm{x}, \mathrm{w}, \mathrm{S}) \rightarrow P(\mathrm{w}, \mathrm{S}))$

If $x$ has the property $P$ in the situation $\mathrm{S}$, the predicate $u s e-f o r(\mathrm{x}, \mathrm{w}, \mathrm{S})$ allows to extend the predicate $P$ to cover the case of $w$ relative to $S$. Each particular extension case is permitted by an entry in the corresponding noun interpretation. Let (26) be such a case.

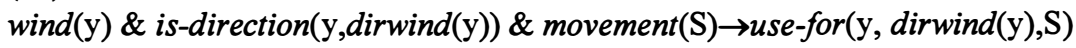


Then (27) is the derivation of the conceptual shift, on the assumption that sailing is a movement situation. As such, it also has a direction, has-direction(dir,S).Note that it is $\mathrm{cmt}$ which is extended here, but the extension is licensed by the situation $S$ of sailing!

$$
\begin{array}{ll}
\text { wind }(\mathrm{a}), \text { movement }(\mathrm{S}) & \text { facts } \\
\text { is-direction }(\mathrm{a}, \operatorname{dirwind}(\mathrm{a})) & \text { by default }(24) \\
\text { use for }(\mathrm{a}, \operatorname{dirwind}(\mathrm{a}), \mathrm{S}) & \text { postulate }(26) \\
\operatorname{cmt}(\mathrm{a}, \mathrm{S}) \rightarrow(\text { use for }(\mathrm{a}, \operatorname{dirwind}(\mathrm{a}), \mathrm{S}) \rightarrow \operatorname{cmt}(\operatorname{dirwind}(\mathrm{a}), \mathrm{S}) & \text { scheme }(25)
\end{array}
$$

The restriction in (23)c. is because the situation of standing is not a movement situation; $\operatorname{cmt}(\operatorname{dirwind}(\mathrm{a}), \mathrm{S})$ is explained by has-direction(dirwind(a), S) due to the fact that movement situations have directions, i.e. sail(S) $\rightarrow$ movement $(\mathrm{S})$, movement $(\mathrm{S}) \rightarrow($ has-direction $(\mathrm{w}, \mathrm{S}) \rightarrow \operatorname{stereotype}(\mathrm{S}, \mathrm{w}, \mathrm{S}))$. Given this, and the instance of (17)b., stereotype(S, dirwind(a),S) $\rightarrow \operatorname{cmt}(\operatorname{dirwind}(\mathrm{a}), \mathrm{S})$, has-direction(dirwind(a),S) $\gg$ cmt(dirwind(a),S) can be established. The conceptual shift scheme (25) contains a Craig interpolant use-for. In other words, Craig interpolants are used as inferential controllers.

\section{Abduction in the lexicon}

It seems that if abductive reasoning is allowed in the lexicon, the overall picture of lexical knowledge changes. It becomes possible to partition the update by lexical information into the general part and the specific part. There is then a uniform mechanism which can be employed to specify the meaning to a necessary degree. It also seems possible to delimit interesting relational aspects of prepositional meaning, the aspects of those prepositions that were called thematic in the paper in contrast to prepositions with intrinsic meanings like locatives in or near. This is a consequence of the role thematic roles play under abduction: they are default classifiers allowing to predict some linguistic properties of situations. It also seems now that abductive reasoning is relevant to argument selection, verb alternations and, as the similarity in the relations to the verb is becoming more transparent under the treatment, also to the formal semantics of case. The profile of the lexicon looks like based on some all-purpose explanatory mechanism. However, there are also difficulties in pursuing this idea. Unconstrained abduction is very complex. In the particular cases studied in the paper there seems to be an efficient restriction in the form of indexing by situations. It remains to be seen whether this restriction is sufficient. There is one more aspect of abductive reasoning. If many hypotheses are present, some are less available than the others. There are different mechanisms of implementing this. Some of them explain the unavailability of particular hypotheses as a particular case of the mechanism which selects hypotheses in general, cf. Blutner (1994). The implications of this approach are yet to be seen. 


\section{Endnotes}

* Part of the research reported here was done during the author's stay as a guest scientist at IBM Institute for Logic and Linguistics at Heidelberg on an invitation by Peter Bosch. My thanks go to Reinhard Blutner, Peter Bosch, Bianka Buschbeck-Wolf, Johannes Dölling, Markus Egg, Peter Gerstl, Michael Herweg, Hans Kamp, Jürgen Kunze, Anke Lüdeling, Henk Zeevat, and Dejuan Wang. By default, the views expressed are those of the author.

${ }^{1}$ I do not want to see situations as objects like individuals or events; they are better thought of as ways of partitioning the world into small chunks. The closest relatives of situations are embeddings in the discourse representation theory of Kamp \& Reyle (1993). However, changes in the model theory required by this view are not subject of this paper.

2 "The view I shall be espousing is that in general the meaning of a sentence only has application (if only, for example, determines the truth conditions) against a background of assumptions and practices that are not representable as a part of the meaning" (Searle, 1980).

${ }^{3}$ Friedman (1990) suggests that people use different, if not unrelated, scales of measuring intervals. How such scales are involved in structuring the situation is a complicated matter, but involved they clearly are: John went to the pub for three years can be interpreted as an iterative event in the situation described by the sentence, cf. Egg and Herweg (1994).

${ }^{4}$ Dowty (1989) refers to what I call thematic structure by the term 'individual thematic roles', and to what I see as $\theta$-roles by the term 'thematic role type'. But the idea is the same, although a representational view is taken in this paper, and a model-theoretic one in Dowty's papers. To quote Dowty (1991) '...thematic role types may form a system of prototypes for classifying events, that is, a set of typical ways in which the various participants of cognitively and culturally relevant types of events interact in these events

${ }^{5}$ In Strigin (1994) it is suggested that constraints on default use can block the portion of structure which is used to provide the causative hypothesis. Constraints are introduced in Poole (1988). But this is only one part of the explanation. The other part requires a reconstruction of Dowty's (1991) proto-roles and argument selection principles in the abductive framework of the present paper. This is still work in progress.

${ }^{6} \mathrm{~A}$ condition imposed by the setting in this paper is that there are at least two theories involved in computing the conextual variants. One is the theory of the underspecified invariant, the other a contextual variant in the situation scheme. This invites the use of Craig interpolants, cf. Kleene (1967) or Fitting (1991). Let $T$ and $T^{\prime}$ be two theories. If $X \rightarrow Y$ is provable in $T \cup T^{\prime}$, and $X$ in in the vocabulary of $T, Y$ in the vocabulary of $T$, then there is a formula $Z$ all individual and predicate parameters of which are both in $T$ and in $T$, and for which holds that $X \rightarrow Z$ is provable in $T$ and $Z \rightarrow Y$ is provable in $T^{\prime}$. This is the Craig lemma, 
and $\mathrm{Z}$ is called a Craig interpolant. In the simplest case encode the way of proving parts of the implication we need using some Craig interpolant at the juncture of the two theories. It is improtant, that this interpolant is motivated. Stereotypical knowledge seems to be a sufficient justification for introducing the interpolant. Another motivation will be introduced in the next section. Hobbs et al. (1993) make use of this device, but in a more unconstrained way.

\section{References}

Bierwisch, Manfred: 1983, 'Semantische und konzeptuelle Repräsentation lexikalischer Einheiten', in R. Ruzicka and W. Motsch (eds.), Untersuchungen zur Semantik, Akademie Verlag, Berlin, pp. 61-99.

Bierwisch, Manfred: 1989, 'The Semantics of Gradation', in M. Bierwisch and E. Lang (eds.), Dimensional Adjectives: Grammatical Structure and Conce ptual Interpretation, Springer, Berlin, pp. 71-271.

Blutner, Reinhard: 1994, 'Systematische Polysemie: Ansätze zur Erzeugung und Beschränkung von Interpretationsvarianten', ms., Berlin.

Dölling, Johannes: 1994, 'Semantic Sorts and Systemmatic Ambiguity'. in Robering, Klaus (ed.) Sorten Typen und Typenfreiheit, Arbeitspapiere zur Linguistik, Vol.30, Institut für Linguistik, Technische Universität Berlin, Berlin, pp. 57-84.

Dowty, David: 1989, 'On the Semantic Content of the Notion "Thematic Role", in Partee, Barbara, Gennaro Chierchia and Ray Tumer, Properties, Types and Meanings: vol. II, pp. 69-130, Kluwer, Dordrecht.

Dowty, David: 1991, 'Thematic Proto-Roles and Argument Selaction', Language, 67 (3), pp. 547-619.

Egg, Markus and Michael Herweg: 1994, A phase-theoretical semantics of aspectual classes, ms., IBM Germany, CLL.

Eroms, Hans-Werner: 1981, Valenz, Kasus und Präpositionen, Carl Winter Universitätsverlag, Heidelberg.

Fitting, Melvin: 1991, First-Order Logic and Automated Theorem Proving, Springer, New York.

Friedman, William: 1990, About Time. Inventing The Fourth Dimension, MIT Press.

Hobbs, J.R., M.E. Stickel, D.E. Appelt and P. Martin: 1993, 'Interpretation as Abduction', Artificial Intelligence 63, pp. 69-142.

Kamp, Hans and Uwe Reyle: 1993, From Discourse to Logic. Introduction to Modeltheoretic Semantics of Natural Language, Formal Logic, and Discourse Representation Theory, Kluwer, Drdrecht.

Kamp, Hans and Antje Roßdeutscher: 1992, 'Remarks on Lexical Sructure, DRSConstruction and Lexically Driven Inferences', Reports of SFB 340 "Sprachtheoretische Grundlagen für die Computerlinguistik, Nr. 21-1992. 
Kleene, Stephen Cole: 1967, Mathematical Logic, Wiley, New York.

Kowalski, Robert and Marek Sergot: 1986, 'A logic-based calculus of events', New Generation Ccomputing 4 , pp. 67-95.

Kunze, Juergen: 1992, 'Einige Betrachtungen zum Komitativ und zu verwandten Konstruktionen', in I. \&. A. S. Zimmermann (eds.), Fuegungspotenzen, Akademie Verlag, Berlin, pp. 111-132.

Mandel, Willi Albert: 1957, Die englischen Präpositionen, Gottschalksche Verlags-buchhandlung, Leverkusen.

Pearl, Judea: 1987, 'Embracing Causality in Formal Reasoning', Proceedings $A A A I^{\prime}$ '87, Washington, Seattle, pp. 360-373.

Peirce, Charles S.: 1955, 'Abduction and Induction', in J. Buchler (eds.), Philosophical writings of C.S.Peirce, Dover books, New York,

Poole, David: 1988, 'A Logical Framework for Default Reasoning', Artificial Intelligence 36, pp. 27-47.

Poole, David: 1989, 'Explanation and prediction: an architecture for default and abductive reasoning', Computational Intelligence 5, pp. 97-110.

Pustejovsky, James and Bran Bogurajew: 1993, 'Lexical Knowledge Representation and Natural Language Processing', Artificial Intelligence, 63, pp. 193-223.

Schröter, Jochen: 1990, Lexikon Deutscher Präpositionen, Verlag Enzyklopädie, Leipzig, (2nd edition).

Searle, John R.: 1980, 'The Background of Meaning', in Searle, John R., Ferenz Kiefer, and Manfred Bierwisch (eds.) Speech Act Theory and Pragmatics, pp. 221-232.

Strigin, Anatoli: 1994, The Semantics of mit, ms, Berlin.

Warrington, Elisabeth: 1978, 'Two categorical stages of object recognition', Perception, 7, pp. 695-705. 